\title{
INTERSEÇÕES ENTRE AS ÁREAS DE CONHECIMENTO DA GERONTOLOGIA, DA SAÚDE E DO TRABALHO: QUESTÕES PARA REFLEXÃO*
}

\author{
Ana Cristina Passarella Brêtas** \\ Eleonora Menicucci de Oliveira***
}

\begin{abstract}
RESUMO: Este estudo tem por finalidade apresentar e discutir alguns referenciais teóricos selecionados referentes às áreas de conhecimento da Gerontologia, da Saúde e do Trabalho. Busca na mediação entre essas áreas compreender o significado do processo de envelhecimento no mercado de trabalho e suas implicações na saúde individual e coletiva. Foi concebido no contexto histórico e politico marcado pelo fenômeno da globalização, com a predominância do pensamento e de politicas de corte neoliberal; portanto, nesta perspectiva discute as transformações produtivas que o mercado de trabalho vem apresentando, com ênfase na questão do desemprego estrutural e suas conseqüências na saúde e no envelhecimento dos indivíduos e da sociedade.
\end{abstract}

PALAVRAS-CHAVE: Saúde, Envelhecimento, Trabalho.

*Trabalho extraído da tese "Envelhecimento, Saúde e Trabalho: um estudo com aposentados e aposentadas" apresentada à Universidade Federal de São Paulo (Unifesp), para obtenção do título de doutor em Enfermagem, sob a orientação da Prof.a Dr.a Eleonora Menicucci de Oliveira, 1999.

**Professora Adjunto da Disciplina de Enfermagem de Saúde Pública e Administração Aplicada à Enfermagem do Departamento de Enfermagem da Unifesp. E-mail acbretas@denf.epm.br

***Professora Adjunto - Livre Docente do Departamento de Enfermagem e do Centro de Saúde Coletiva da Unifesp. 
INTRODUÇÃO

Esse estudo tem por finalidade apresentar e discutir alguns referenciais teóricos selecionados referentes às áreas de conhecimento da Gerontologia, da Saúde e do Trabalho. Busca na mediação entre essas áreas compreender o significado do processo de envelhecimento no mercado de trabalho e suas implicações na saúde individual e coletiva; neste momento histórico marcado pelo fenômeno da globalização, com a predominância do pensamento e de políticas de corte neoliberal. Trabalhamos com a área temática da Gerontologia, contextualizando sua origem, campo teórico, mas sobretudo discutimos o significado do envelhecimento. Feito isso, introduzimos à questão do envelhecimento a área da Saúde, onde buscamos em diferentes conceitos construir um significado individual e coletivo ao termo e a partir dal estabelecemos relações teóricas com o processo de envelhecimento do ser humano e da sociedade. Agregamos à essa discussão a área temática do Trabalho, direcionando o nosso olhar para sua conceituação marxista discutindo as transformações produtivas que o mercado de trabalho vem apresentando, com ênfase na questão do desemprego estrutural e suas implicações na saúde e envelhecimento dos indivíduos e da sociedade.

\section{GERONTOLOGIA}

A Gerontologia é a área do conhecimento que tem por objetivo estudar o processo de envelhecimento humano; busca basicamente compreender as questões do como e do porque se envelhece. É uma área nova, concebida em 1908 por Metchnikoff (SAYEG, PEREIRA, 1994). No Brasil, começa se consolidar em meados do século $X X$, de forma lenta, com difícil inserção nas Universidades dado à resistência apresentada por professores - notadamente clínicos (GOMES, 1994). GUIMARÃES (1997) ao avaliar a área como campo de investigação salienta que a produção científica brasileira relacionada ao envelhecimento é limitada, refletindo muito mais o esforço individual dos(as) pesquisadores(as) do que o resultado de apoio de órgãos financiadores de pesquisa.

É importante salientar que a Gerontologia enquanto área do conhecimento tem característica interdisciplinar. Tendo por objeto o envelhecimento, se constitui em uma área ampla e complexa, requerendo a dimensão de várias ciências na sua construção teórica. 
Com o objetivo de subsidiar teoricamente a reflexão sobre o significado do envelhecimento realizamos uma revisão conceitual sobre o tema. Segundo FERREIRA (1985) "é o ato ou efeito de envelhecer", para CASUCCI (1991) é o processo através do qual o indivíduo se modifica em função do tempo. BORBA (1991) relata que o verbo envelhecer pode indicar um processo ou uma ação-processo tomando o significado de "fazer parecer velho, dar as características da velhice; tornar-se velho; fazer perder sua força, seu interesse; atribuir uma idade superior à idade real"; FERREIRA (1985) acrescenta "avelheantar, perder a frescura, o viço, durar muito tempo, tornar-se desusado ou inútil".

Para CARVALHO FILHO e ALENCAR (1994) o envelhecimento "é um processo dinâmico e progressivo onde há modificações tanto morfológicas como funcionais, bioquímicas e psicológicas que determinam progressiva perda da capacidade de adaptação do indivíduo ao meio ambiente, ocasionando maior vulnerabilidade e maior incidência de processos patológicos que terminam porlevá-los à morte"; BENTOV e colaboradoras (1993) fazem uma distinção entre o ato de envelhecer e o ato de tornar-se velho(a), para elas, o envelhecimento compreende todas as mudanças biológicas que ocorrem com o passar do tempo, enquanto tornar-se velho(a) tem uma significância social, responsável por sentimentos pouco relacionados com o processo biológico de envelhecimento. ALONSO (1995) salienta que o envelhecimento é um fenômeno complexo, dinâmico e pluridimensional, onde intervém não apenas fatores de ordem biológica ou psíquica, mas fatores de ordem social. Segundo ROBLEDO (1994) o envelhecimento não tem uma causalidade única, não é doença nem um erro evolutivo, é um processo dinâmico, progressivo e irreversivel em que interagem múltiplos fatores biológicos, psicológicos e sociais.

Podemos observar nessas definições que o termo envelhecimento é visualizado enquanto um processo complexo, pluridimensional, carregado hegemonicamente pelo simbolismo de perdas e por conotaçōes negativas. Acreditamos, no entanto, que é revestido não apenas por perdas mas também por aquisições individuais e coletivas, fenômenos inseparáveis e simultâneos. Para BEAUVOIR (1990) definir para o ser humano o que é progresso ou regressão "supõe que se tome como referência um determinado fim; mas nenhum é dado a priori, no absoluto. Cada sociedade cria os seus próprios valores: é no contexto social que a palavra 'declínio' pode adquirir um sentido preciso". Assim na perspectiva dialética o todo e as partes se imbricam na compreensão do processo de envelhecimento, pois se o ato de envelhecer é individual, o ser humano vive na esfera coletiva e como tal, sofre as influências da sociedade. 
Destacamos que o ato de envelhecer implica em mudanças constantes, sendo que saber lidar com as perdas, buscando novas aquisições durante todo o processo de envelhecimento é o que o torna saudável. Um envelhecimento será cada vez mais satisfatório quanto maior for o poder do individuo assimilar e não renunciar às mudanças físicas, psicológicas e sociais, adaptando-se, sem sofrer em demasia, aos novos papeis sociais que desempenhará no decorrer da sua vida. (PERLADO, 1995).

$\mathrm{Na}$ busca por procurar delimitar o início do processo de envelhecimento, duas concepções teóricas prevalecem, uma delas, fundamentada na área das ciências biológicas, defende que começa-se a envelhecer quando se termina de crescer, mais ou menos por volta dos 22, 25 anos de idade; a outra, baseada na área das humanidades salienta que o processo de envelhecimento inicia-se na concepção e termina na morte.

Fundamentamos este trabalho nessa segunda dimensão, uma vez que entendemos que o envelhecimento é um fenômeno natural e processual, que vai do útero ao túmulo. Para nós, o processo de envelhecimento é compreendido como o processo de vida, ou seja envelhecemos porque vivemos, muitas vezes sem nos darmos conta disto. O processo de envelhecimento contém, pois, a fase da velhice mas não se esgota nela. A qualidade de vida e, consequentemente, a qualidade do envelhecimento relacionam-se com a visão de mundo do indivíduo e da sociedade em que ele está inserido, bem como com o "estilo de vida" conferido a cada ser, (BRÊTAS, 1997) e é nesse contexto que buscamos compreender o processo de envelhecimento e suas implicações para a saúde individual ou coletiva.

BOBBIO (1996) reforça essa visão de envelhecimento enquanto processo de vida quando relata que a velhice não é uma cisão em relação à vida precedente, e sim uma continuação da adolescência, da juventude, da maturidade que podem ter sido vividas de diversas maneiras. Segundo WAGNER (1992) o ser humano "forma-se durante a vida pela interação de fatores que o caracterizam como ser biológico, (...), psicológico (...) e irá ser moldado também sob a influência do meio físico e social onde se desenvolverá. É portanto de uma incrivel e variada gama de possibilidades que surgirão modos de ser, de pensar, de sentir e de agir das pessoas, (...), influenciadas por todos estes elementos, sobre os quais elas poderão se sentir mais ou menos controladas".

Partindo do pressuposto de que o envelhecimento é um fenômeno natural que se inicia no útero e termina no túmulo, portanto é o processo da vida (FEATHERSTONE, 1998), observamos que ele se corporifica por meio da existência do corpo humano, onde a 
visibilidade do envelhecimento ocorre através da imagem do corpo. Para FEATHERSTONE (1994) "o nosso movimento através da vida depende das vicissitudes do corpo. Este é um processo que tem uma finitude inevitável. Nós nascemos, vivemos e morremos (...)", portanto a vida e o envelhecimento apresentam-se como um processo de mão única, sem retorno. Considerando que a vida não é só biológica, ela é social e culturalmente construída, assim como a imagem atribuída ao corpo, detectamos que o simbolismo presente na imagem corpórea, bem como os estágios da vida apresentam diferentes significados e duração.

FEATHERSTONE (1998) adverte que enquanto pesquisadores(as) devemos estar atentos(as) para não generalizar ou universalizar demasiadamente o conceito de envelhecimento. Para ele "podemos falar de nossas próprias experiências, mas é preciso movimentarmo-nos com cuidado quando tentamos relacionar nossa experiência pessoal com a da humanidade. Podemos dizer algo sobre experiências comuns, como nascer, envelhecer, morrer; mas não muito mais do que isso".

Ao trabalharmos com a dimensão social do envelhecimento, percebemos que existem diferenças significativas nas formas como as vidas dos indivíduos são periodizadas. Cada sociedade define os períodos que compōem o ciclo da vida dos seres humanos, os quais sofrem influências culturais, sociais e históricas. Basicamente três são os princípios utilizados pelas sociedades para organizar os ciclos da vida: a idade cronológica, a idade geracional e os niveis de maturidade. Segundo DEBERT (1994) "o processo de agrupar pessoas em função de sua geração é totalmente distinto de agrupar pessoas em função do estágio de maturidade ou da idade cronológica".

As idades cronológicas são baseadas em um sistema de datação, surgem nas sociedades modernas, como veremos a seguir, prevalecendo nas culturas ocidentais. "São um mecanismo básico de atribuição de status (maioridade legal), de definição de papeis ocupacionais (entrada no mercado de trabalho), de formulação de demandas sociais (direito à aposentadoria), etc. (...). A idade cronológica só tem relevância quando o quadro político jurídico ganha precedência sobre as relaçōes familiares e de parentesco para determinar a cidadania." (DEBERT, 1994). Os estágios de maturidade, por sua vez, são observados com mais freqüência nas estruturas sociais das sociedades não ocidentais, onde são consideradas as capacidades dos indivíduos realizarem certas tarefas. Vale destacar que a validação cultural desses estágios é feita mediante uma autorização para o exercício das práticas como casar, caçar, participar do conselho dos velhos - sendo que o ritual de passagem para o outro estágio é definido, majoritariamente, pelos mais velhos que fazem parte destas 
sociedades. A idade geracional pode ter como referência a estrutura familiar, onde "um pai é um pai, um irmão é um irmão independentemente de sua idade cronológica ou estágio de maturidade" (DEBERT, 1994); como pode também implicar em um "conjunto de mudanças que impõe singularidades de costumes e comportamentos a determinadas gerações. Daí falar-se em geração do pós-guerra, da televisão, de 68. A geração não se refere às pessoas que compartilham a idade, mas que vivenciaram determinados eventos que definem trajetórias passadas e futuras" (DEBERT, 1994).

Acreditamos que a geração, mais do que a idade cronológica, permite que os seres humanos tomem consciência de suas experiências extra-familiares, remetendo-os à vivências coletivas enquanto grupos responsáveis por mudanças de comportamento e construção de memórias coletivas incorporadas na esfera social e política da história da humanidade.

Desta forma, retomando a questão de que as sociedades adotam princípios diversos para periodizar o ciclo da vida dos indivíduos, julgamos importante apresentar características básicas desse processo nas sociedades pré-moderna, moderna e pós-moderna.

Observamos que nas sociedades pré-modernas a periodização da vida fundamentava-se nos princípios de geração e tradição, sendo que o curso da vida não apresentava estágios muito diferenciados; o status social era mais significativo do que a grade etária. É ilustrativo o exemplo do rei Luís XIV que, mesmo quando criança, era tratado como adulto e detinha poder, enquanto um escravo, independente de sua idade cronológica, não conseguia durante toda sua vida sair da infância, era classificado como dependente, tido como ser inferior (FEATHERSTONE, 1994, 1998). ARIĖS (1991) ilustra essa fase ao descrever que a infância foi uma categoria criada a partir do século XIII, desenvolvendo-se gradativamente ao longo dos séculos, momento em que as crianças passam a ser separadas do mundo dos adultos deixando de serem tratadas, de se vestir, trabalhar, sofrer punições como eles.

Nas sociedades modernas, por sua vez, as vidas são periodizadas por meio da definição de grades etárias. Essas sociedades caracterizam-se pelo processo de industrialização, urbanização e administração pública da vida das pessoas, onde os seus corpos passam a ser controlados e administrados, sendo que os estágios da vida são claramente demarcados pelas idades cronológicas. Iniciam-se os registros dos nascimentos, mortes, doenças; segundo FOUCAULT (1993) os corpos começam a ser registrados e consequentemente disciplinados. Para FEATHERSTONE (1998) "a partir do 
desenvolvimento da modernidade, possuímos uma formação cronológica do curso da vida, embutida de modo muito forte em nossa percepção". Observamos na sociedade ocidental de uma maneira geral, em particular na brasileira, que são normatizadas as idades para o ser humano entrar na escola, assistir a determinados filmes, espetáculos teatrais, dirigir automóveis, possuir título de eleitor, responder a processos criminais; enfim, a sociedade disciplina os corpos, controlando cronologicamente as fases da vida dos indivíduos. Nesta seqüência de raciocínio temos que a Organização Mundial de Saúde convencionou para países do Terceiro Mundo o corte de 60 anos de idade como delimitador da velhice (WHO, 1984), também adotado pelo governo brasileiro na Lei n 8.842 que dispõe sobre a Política Nacional do Idoso (BRASIL, 1994). Apesar disso, observamos que vários direitos conquistados pelos(as) idosos(as) no Brasil tem o recorte etário de 65 anos, citamos como exemplo a garantia a gratuidade dos transportes coletivos urbano e assistência geriátrica e gerontológica prestada em parcela significativa dos Serviços Públicos de Saúde. O voto facultativo e a aposentadoria compulsória dos servidores públicos civis ocorrem com setenta anos de idade (BRASIL, 1988); o Estado fixa ainda a idade em que o(a) trabalhador(a) tem direito a uma aposentadoria; os(as) empregadores(as) por sua vez definem a idade de exclusão dos(as) trabalhadores(as) do mercado de trabalho e uma vez despedidos(as) não conseguem mais se reinserir na economia formal dado o fator etário. Podemos afirmar que essa manipulação das categorias etárias nas sociedades modernas é arbitrária e traz no seu bojo uma verdadeira luta política, onde o que esta em jogo é a redefinição dos poderes ligados a grupos sociais distintos em diferentes momentos do ciclo de vida (DEBERT, 1994).

Atualmente vivemos um periodo de transição entre a modernidade e a pósmodernidade no que diz respeito a compreensão do curso da vida e as fronteiras entre as idades, onde observamos uma maior flexibilidade e variedade entre as faixas etárias, implicando em diversidades de hábitos e estilos de vida. Quanto às pessoas mais velhas, diferentes padrões ou modelos de velhice e envelhecimento convivem simultaneamente na sociedade, prevalecendo o pensamento de que a idade não é um indicador de normas de comportamento e estilos de vida, bem como as doenças físicas e o declínio mental deixam de ser característica desta faixa etária visto que podem acometer pessoas das mais diversas idades. Desta forma assistimos nas sociedades pós-modernas a descronologização geral do curso da vida. Entretanto DEBERT (1997) alerta que esse processo precisa ser visualizado com as devidas ressalvas, pois as idades ainda são um marco da organização social, portanto é necessário tomar cuidado para não anular conquistas como o Estatuto do Menor e do Adolescente, direito à aposentadoria entre outros, em nome de projetos universalistas de valorização da descronologização das sociedades. 
Acreditamos que esses princípios utilizados pelas sociedades para organizar os ciclos da vida dos seres humanos respondem em parte à problemática do processo de envelhecimento individual e populacional. Considerando a heterogeneidade das sociedades, defendemos que as diversidades de situações de gênero, de classe social e de etnia precisam também ser consideradas pois são responsáveis pela delimitação do espaço social que o individuo ocupa na sociedade.

Retomando a assertiva de FEATHERSTONE (1994) de que "o nosso movimento através da vida depende das vicissitudes do corpo", onde o curso da vida é um processo inevitavelmente finito, deduzimos que por mais que a vida seja social e culturalmente construída de diversos modos, a finitude do ser é expressa pelas perdas corpóreas, que são diferentes nos corpos dos homens e das mulheres, dos(as) explorados(as) e dos(as) exploradores(as). Acreditamos que a integridade física e psíquica do corpo, representadas pela capacidade de autonomia do ser humano no desenvolvimento de habilidades cognitivas, controles fisiológicos do organismo e controles emocionais, é o marco delimitador entre o processo de envelhecimento saudável e doente, além do que a perda desses controles e capacidades leva a estigmatização das pessoas idosas. (FEATHERSTONE, 1994). BEAUVOIR (1990) descreve que "a velhice aparece mais claramente para os outros, do que para o próprio sujeito; ela é um novo estado de equilíbrio biológico: se a adaptação se opera sem choques, o individuo que envelhece não a percebe".

Resumindo temos que o envelhecimento humano só é compreendido na sua totalidade à luz da mediação teórica entre várias áreas do conhecimento humano, sendo que precisa ser visualizado nas esferas do individuo e da sociedade e nas perspectivas analíticas de gênero, geração, classe social e etnia. É um processo contínuo e finito, onde a imagem do corpo tem uma significância fundamental e a perda da autonomia (capacidade de tomar decisões) é o delimitador entre a saúde e a doença, responsável pela estigmatização dos(as) idosos(as) na sociedade.

\section{SAÚDE E ENVELHECIMENTO}

Iniciamos a discussão sobre Saúde e Envelhecimento buscando em uma primeira instância conceituar saúde e descrever os significados que vem apresentando no decorrer da história. Destacamos que a consideramos como um campo ideológico, historicamente concebido, socialmente construido e que espelha o resultado das politicas sociais e econômicas adotadas pelos paises e ditadas por agrupamentos econômicos internacionais. (BRÊTAS, 1994). Pode-se afirmar que a área da saúde veicula interesses e visões de 
mundo diversas, produto de conflituosas relações sociais construídas por atores e atrizes políticos com distintos projetos e objetivos. Majoritariamente identificamos a disputa entre dois grupos ideológicos, um representado pelo pensamento neoliberal que defende o modelo privativista e elitista das práticas de saúde, com ênfase na utilização de tecnologia de ponta, o outro, construido à luz do socialismo, idealiza um sistema de saúde público, eqüânime, de alcance coletivo. Desta forma, a saúde não é um campo neutro mas um campo de saber portanto local de disputa de relações de poder. Entretanto, se por um lado compreendemos a saúde como um processo amplo e social, acreditamos que é também uma experiência subjetiva e individual, conhecida intuitivamente, dificilmente descrita ou quantificável. Segundo CAPRA (1995) "embora nós todos saibamos o que significa sentirmo-nos saudáveis, é impossivel definir precisamente tal estado". Desta forma, tal qual o envelhecimento, a saúde é um fenômeno multidimensional, com características individuais e coletivas, que envolve de forma dialética aspectos físicos, psicológicos e sociais da natureza humana.

Há muito diferentes autores(as) buscam conceituá-la; FERRARA e colaboradores (1976) delineiam quatro fases para explicar e contextualizar a evolução histórica da saúde: o período instintivo ou empírico; o sacerdotal ou místico; o hipocrático e o contemporâneo. Apesar desses autores relacionarem os períodos à comunidades primitivas, à barbárie, à Idade Média e à contemporaneidade, a nossa experiência enquanto sanitarista leva-nos a concluir que estas fases estão presentes ainda hoje no imaginário coletivo da sociedade. Os clientes dos serviços de saúde expressam suas inquietações frente ao processo saúde doença, explicando seus achados por meio do místico, do empírico, da força da natureza, estabelecendo um caráter dialógico (HABERMAS, 1987), com o discurso medicalizado da área, construído a partir da modernidade.

Trazemos aqui alguns exemplos coletados em nossa prática cotidiana em serviços de saúde e nas comunidades carentes com favelados e moradores de rua, fundamentadas no referencial teórico da comunicação dialógica, ou seja, o diálogo entre o discurso do senso comum e o discurso científico dos profissionais da saúde. No que se refere às explicações sobre o porque se perde a saúde temos: "foi Deus que quis", "é força de mau olhado", "os micróbios entraram pela pele", "também, o desemprego, a fome, tudo isso ajuda", "foi erro do médico", "o problema é a sujeira", "dormindo no chão com esse frio é pneumonia certa", entre outros; da mesma forma "conselhos" para recuperá-la surgem com freqüência: "benzer é muito bom", "o melhor é benzetar", "sem rezar o mal não vai embora", "é preciso tomar remédio de médico, senão não sara", "precisa deixar a casa bem limpa". 
Depreendemos da riqueza desses discursos que as concepções de saúde da clientela por nós assistida tem a ver com as suas raízes tradicionais, com suas experiências de vida, de consumo de serviços, de inserção ou exclusão do mercado de trabalho; de seu papel social como usuários(as) dos serviços de saúde. Ignorar tal questão significa ampliar e reforçar a distância que existe entre as categorias analíticas e empíricas que co-habitam o universo da área da Saúde.

Em 1946 a Organização Mundial da Saúde, através da Carta de Declaração de Princípios (OMS, 1976), estabelece que "saúde é um estado de completo bem-estar físico, mental e social, e não apenas a ausência de distúrbios ou doenças”. É necessário estar atento ao contexto histórico em que esse conceito foi concebido, após a Segunda Grande Guerra, em um momento onde os povos buscavam a reconstrução de tudo que havia sido destruído, na esfera dos corpos individuais e da sociedade como um todo. Indubitavelmente é um conceito polêmico, se por um lado confere uma dimensão ampla à saúde, valorizando os aspectos biológico, psicológico e social, por outro descreve um objetivo inatingível; por ela, todos nós seremos considerados doentes, dado as condições planetárias em que vivemos, influenciadas pela desigualdade social, discriminação de gênero, geração, etnia, repressão e problemas ambientais.

Vale destacar que em 1978, durante a Conferência Internacional sobre Cuidados Primários de Saúde realizada em Alma-Ata, na extinta URSS, o conceito criado pela OMS é enfaticamente reafirmado. Na ocasião é proposto que a saúde seja concebida "como um direito humano fundamental", sendo considerada uma "meta social mundial, cuja realização requer a ação de muitos outros setores sociais e econômicos, além do setor da saúde". Salientam ainda que "uma das principais metas sociais dos governos, das organizações internacionais e toda a comunidade mundial na próxima década deve ser a de que todos os povos do mundo, até o ano 2000, atinjam um nível de saúde que Ihes permita levar uma vida social e economicamente produtiva". (OMS, 1979).

Em 1978 reivindicar "saúde para todos no ano 2000" (OMS, 1979), poderia ser visto como uma utopia viável, quiçá um direcionamento político planetário não concretizaria tal meta. Em 1999 temos a certeza de que faltou vontade política dos governantes e das elites dos mais diversos níveis para mobilizar recursos, estimular cooperação entre os povos. Ao contrário, presenciamos nas duas últimas décadas um processo sem igual de discriminação entre os povos e ampliação das fronteiras da desigualdade social. O objetivo não foi atingido. 
FERRARA e colaboradores, na década de 70, propõem um novo conceito para saúde. Para eles, ela "é o contínuo agir do homem frente ao universo físico, mental e social em que vive, sem regatear um só esforço para modificar, transformar e recriar aquilo que deve ser mudado" (FERRARA et al., 1976). Concedem assim ao conceito uma dimensão dinâmica e dialética, valorizando o papel dos seres humanos na manutenção e transformação da saúde (individual e coletiva), os colocando como atores sociais do processo da vida.

Buscando exemplificar o paradoxo entre as duas definições de saúde trabalhadas, a da OMS e a de FERRARA, trazemos à luz uma situação hipotética mas que sem dúvida faz parte da nossa realidade: uma pessoa com 65 anos de idade, portadora de hipertensão arterial e diabetes, inevitavelmente será considerada doente se analisarmos a situação sobre o prisma da OMS; se por outro lado adotarmos FERRARA como norte da análise, diremos que dependendo da forma com que lida com o processo de envelhecimento e as doenças hipertensão e diabetes, será ou não considerada doente. Na maior parte das vezes o que temos é um ser humano portador de doenças e não o contrário um indivíduo doente. É importante notar que esses conceitos trazem ideologias implicitas, que definirão as ações de saúde desenvolvidas pelas equipes nos serviços de saúde; assim, destacamos que a segunda visão tem prevalecido na maior parte dos serviços. Pensando o processo de envelhecimento nessas perspectivas, pela OMS dificilmente teremos um indivíduo saudável, pois na medida em que envelhece seu organismo sofre perdas de ordem biológica, fisiológica, bioquímica, entre tantas outras, contribuindo para o desequilibrio físico, mental, social, gerando mal estar. Quando pensamos o mesmo processo, do útero ao túmulo, na ótica proposta por FERRARA e colaboradores, o indivíduo será tanto mais saudável quanto mais reagir aos estímulos biológicos, psicológicos e sociais, buscando formas de criar, recriar e transformar tudo o que precisa ser mudado.

Para uma melhor e mais rigorosa discussão conceitual, introduzimos CANGUILHEM neste diálogo. Ele propõe que em se tratando de definir a saúde é necessário partir da dimensão do ser, pois é neste contexto que ocorrem as definições do que é normal ou patológico. O que é considerado normal em um individuo pode não ser para outro; não há rigidez nesse processo, "a fronteira entre o normal e o patológico é imprecisa para diferentes individuos considerados simultaneamente, mas é perfeitamente precisa para um único e mesmo individuo considerado sucessivamente" (CANGUILHEM, 1995).

Desta maneira podemos ir deduzindo que o ser humano precisa se auto conhecer, necessita saber avaliar as transformações que o seu corpo sofre e identificar os sinais 
expressos por ele. Esse processo é viável apenas na perspectiva relacional, uma vez que o normal e o patológico só podem ser apreciados numa relação. Considerando essa dimensão nas práticas de saúde, os profissionais de saúde precisam estar preparados para atender as particularidades individuais, mesmo em situações que demandem ações coletivas

Para CANGUILHEM (1995) o que caracteriza a saúde "é a possibilidade de ultrapassar a norma que define o normal momentâneo, a possibilidade de tolerar infrações à norma habitual e de instituir normas novas em situações novas". Para ele "estar em boa saúde é poder cair doente e se recuperar; é um luxo biológico”. Onde “(...) a possibilidade de abusar da saúde faz parte da saúde".

Nesta dimensão a saúde expressa um sentimento de segurança na vida, uma vez que representa "uma maneira de abordar a existência com uma sensação não apenas de possuidor ou portador, mas também, se necessário, de criador de valores, de instaurador de normas vitais". (CANGUILHEM, 1995). A saúde torna-se a capacidade que o ser humano tem de gastar, consumir, a própria vida. CANGUILHEM (1995) citando Kant salienta que o ser humano não sente o bem-estar, pois esse é a consciência de viver, é o seu impedimento que provoca a reação do indivíduo com vistas a restabelecê-lo. Vale destacar que a vida não admite a reversibilidade, ela aceita apenas reparações. Cada vez que o indivíduo fica doente esta reduzindo o poder que tem de enfrentar outros agravos, ele gasta o seu seguro biológico, sem o qual não estaria nem mesmo vivo.

Mesmo pensando em saúde nas dimensões do coletivo e do planeta é imprescindivel considerar o indivíduo como ponto de referência. Só existe o social e o planetário porque existe o ser. Pensemos o envelhecimento nesta lógica, por mais que se aborde a perspectiva populacional, quem envelhece é o indivíduo e como tal deve ser considerado. A maneira como cada ser na sua especificidade "gasta" a vida será o delimitador da qualidade do envelhecimento; vivemos porque consumimos vida, essa é a essência do pensamento de CANGUILHEM. Quem não consome a vida não a tem, não envelhece, simplesmente porque não existe enquanto ser. Segundo CAMPOS (1997) "a utopia do corpo conservado para sempre só se realiza com a mumificação. Dura-se para sempre, só que à custa do movimento, do prazer, da dor e da vida".

Seguindo o raciocínio e o pensamento de CANGUILHEM, acreditamos que a cidadania é obtida plenamente quando o indivíduo conhece o seu próprio corpo e a partir daí passa a ter condições para praticar e reivindicar ações que assegurem a qualidade da 
sua existência. Assim, visualizamos o profissional da saúde como alguém capaz de instrumentalizar mediante práticas de saúde os(as) usuários(as) e excluídos(as) do sistema de saúde sobre o funcionamento do corpo, ampliando as possibilidades de sobrevivência e de qualidade de vida dos seres humanos por ele(a) assistidos(as).

Nesta linha de reflexão CAMPOS (1997) ressalta que a saúde "pressupõe uma certa capacidade de utilização de instrumentos naturais e artificiais - socialmente construidos, como o foram a Clínica e a Saúde Pública - com o intuito de afastar a dor, o sofrimento e a morte", onde o objetivo de todo o trabalho na área da saúde se direcionasse para ampliar a capacidade de autonomia dos clientes (CAMPOS, 1997). Para o autor "as instituições de saúde deveriam existir tanto para ajudar cada cliente a melhor utilizar os recursos próprios, partindo sempre do reconhecimento da vontade e desejo de cura de cada um, como para Ihes oferecer recursos institucionais também voltados para melhorar as condiçōes individuais e coletivas de resistência à doença" (CAMPOS, 1997).

Pensar em autonomia dos seres na ótica da saúde e do envelhecimento remetenos a duas reflexões: a primeira implica em visualizar não só o usuário dos serviços, mas também o profissional da saúde como seres autônomos, portanto capazes de gerir sua própria vida; a segunda introduz ao tema a noção de auto-cuidado como uma maneira dos indivíduos assumirem para si o controle do seu próprio corpo, no entanto sem desresponsabilizar o Estado do seu dever com a saúde, no sentido de "prover as condições indispensáveis ao seu pleno exercicio" (MINISTÉRIO DA SAÚDE, 1991).

CAPONI (1997) salienta que o ser humano se distingue dos animais pelo fato de existir além de viver; ou seja, o ser humano vive obedecendo e questionando um sistema de regras socialmente instituídas. Nesta perspectiva dialética do viver - existir - viver, a dimensão do auto-cuidado assume um significado importante, pois é por meio dele que o ser mantém seu corpo vivo, sua saúde e garante a sua existência. A possibilidade da manutenção do auto-cuidado durante todo o processo de vida é condição básica para um envelhecimento bem sucedido, visto que como mencionamos anteriormente a integridade física e psiquica do corpo, representadas pela capacidade de autonomia do ser humano no desenvolvimento de habilidades cognitivas, controles fisiológicos do organismo e controles emocionais, é o marco delimitador entre o processo de envelhecimento saudável e o patológico, além do que a perda desses controles e capacidades leva a estigmatização das pessoas idosas. (FEATHERSTONE, 1994). 
Desta forma um grande desafio posto para os profissionais da saúde que trabalham com o processo de envelhecimento é saber discernir como se pode cuidar sem possuir; em outras palavras, "como cuidar sem anular a autonomia do cliente"? (CAPONI, 1997).

\section{TRABALHO, SAÚDE E ENVELHECIMENTO}

Introduzimos agora, no diálogo entre a Saúde e o Envelhecimento a área temática do Trabalho. Trabalhamos à luz do pensamento marxista, por considerarmos ser a teoria que melhor expressa as atitudes e valores frente a essa temática.

Para MARX (1998) o trabalho "é um processo de que participam o homem e a natureza, processo em que o ser humano, com sua própria ação, impulsiona, regula e controla seu intercâmbio material com a natureza. (...). Põe em movimento as forças naturais de seu corpo - braços e pernas, cabeça e mãos -, a fim de apropriar-se dos recursos da natureza, imprimindo-Ihes forma útil à vida humana". Para o autor a utilização da força de trabalho é o próprio trabalho e como tal é uma atividade exclusivamente humana.

Segundo ENGELS (1990) o trabalho é o fundamento da vida humana; afirma que sob determinado aspecto, o trabalho criou o próprio homem. Para ele, primeiro o trabalho e depois a palavra articulada foram os marcos decisivos da transformação evolutiva do cérebro do macaco em cérebro humano. Descreve que o trabalho passa a ser concebido na medida em que uma raça de macacos antropomorfos, já em estado de desenvolvimento muito elevado, consegue liberar as mãos e paulatinamente, no decorrer de milhares de anos, utilizá-las com destreza e habilidade para transformar a natureza usando instrumentos elaborados. Assim, "a mão não é apenas um órgão de trabalho, é também produto dele" (ENGELS, 1990).

O ser humano se distingue dos outros animais porque além de utilizar o esforço do corpo no processo de trabalho, utiliza a mente é capaz de projetar a transformação que fará ao material sobre o qual opera, antes de iniciá-la. Ele imprime a sua vontade ao processo de trabalho. (MARX, 1998; ENGELS, 1990).

Pode-se dizer que a sociedade humana surge em função do trabalho. Para MARX (1998) a vida em sociedade consiste nos seres humanos viverem uns ao lado dos outros para cumprir de certo modo três funções básicas: 1. produzir coisas que necessitam para 
viver por meio do seu trabalho; 2 . distribuir entre si os produtos que produziram e 3 . consumir os produtos distribuídos segundo suas necessidades. Salienta no entanto que o que distingue uma organização social da outra é a maneira como se produz e como se distribuem os produtos fabricados.

Para pensar a articulação entre Envelhecimento, Saúde e Trabalho, tomamos como ponto de partida a reflexão sobre a sociedade capitalista, tendo em vista que é a hegemônica no contexto histórico em que vivemos.

Para MARX (1998) a essência do capitalismo é a exploração do trabalho. Adverte que o processo de trabalho é composto fundamentalmente por três elementos: "1. a atividade adequada a um fim, isto é o próprio trabalho; 2. a matéria a que se aplica o trabalho, o objeto de trabalho e 3. os meios de trabalho, o instrumental de trabalho". Considera que os meios de trabalho são responsáveis pela distinção entre as diferentes épocas econômicas, uma vez que servem para medir o desenvolvimento da força de trabalho humana e também indicar as condições sociais em que o trabalho se realiza. Meios de trabalho em sentido lato, são todas as condições materiais necessárias à realização do processo de trabalho.

O processo de trabalho, quando ocorre como processo de consumo da força de trabalho pelo capitalista, caracteriza-se por dois fenômenos: no primeiro o(a) trabalhador(a) trabalha sob controle do capitalista, a quem pertence seu trabalho; no segundo, o produto do trabalho é propriedade do capitalista e não do(a) trabalhador(a). Desta forma, o(a) trabalhador(a) está continuamente sendo explorado(a) pelo capitalista, mesmo sendo um ser livre; por não ser dono dos meios de produção só pode sobreviver empregando-se em troca de salário. Segundo HUBERMAN (1986) "é evidente que o trabalhador não se vende ao capitalista (isso faria dele um escravo), mas vende a única mercadoria que possui-sua capacidade de trabalhar, sua força de trabalho".

Essa reflexão nos leva a introduzir a questão do valor da força de trabalho. Para MARX (1985), como todas as outras mercadorias, o valor da força de trabalho é determinado pela quantidade de trabalho necessária para a sua produção, que é avaliado "pelo valor dos artigos de primeira necessidade indispensáveis para produzir, desenvolver, conservar e perpetuar a força de trabalho" (MARX, 1985). Vale destacar que a utilização dessa força de trabalho só é limitada pela energia vital e a força física do(a) trabalhador(a).

Ao comprar e pagar a força de trabalho, o(a) capitalista adquire o direito de utilizála como mercadoria; entretanto, se o valor pago refere-se à quantidade de horas de trabalho 
necessárias à conservação ou reprodução desta força de trabalho, bem como ao tempo socialmente necessário para a produção de determinada mercadoria, o tempo que o(a) trabalhador(a) produzir a mais é considerado lucro do capitalista. É o que Marx (1985 e 1998) chamou de produção da mais-valia. Assim, a mais-valia não nasce durante a compra ou a venda da mercadoria, mas muito antes, durante a sua produção. Desta forma temos que a força de trabalho não apenas transmite seu próprio valor enquanto mercadoria, mas também acrescenta o da mais-valia.

Para HUBERMAN (1986) a teoria da mais-valia de Marx demonstra como o trabalho é explorado na sociedade capitalista, onde o modo de produção determina o caráter geral dos processos de vida social, politica; entre outros, enfim, é a base de toda sociedade. Destaca como a grande contradição da sociedade capitalista o fato de que "enquanto a produção em si é cada vez mais socializada, o resultado do trabalho coletivo, a apropriação, é privado, individual. O trabalho cria, o capital se apropria". (HUBERMAN, 1986). Segundo MARX e ENGELS (1987) apenas uma revolução da classe operária poderia acabar com a exploração dos(as) trabalhadores(as). Para eles o Estado existe para defender os interesses dos(as) capitalistas, pois a classe que domina economicamente também domina politicamente - "é o poder político (...) organizado de uma classe para a opressão de outra" (MARX, ENGELS, 1987).

Dados históricos nos levam a concluir que a realidade social em qualquer país capitalista é marcada pela desigualdade social, fruto da má distribuição de renda, onde poucos ganham muito e muitos vivem com muito pouco. VIEIRA (1997) contextualiza essa questão ao citar dados do relatório do Programa das Nações Unidas para o Desenvolvimento (PNUD), que ao analisar "174 países com dados referentes a 1993," constatou que "as 358 pessoas mais ricas do mundo têm mais dinheiro do que países com 45\% de toda a população do planeta"(VIEIRA, 1997). O Brasil, por sua vez, também apresenta contrastes e profundas desigualdades sociais. O relatório sobre o Desenvolvimento Humano elaborado pela ONU em 1996 revela que o país detém uma das piores concentrações de renda do mundo, onde a média dos $10 \%$ mais ricos da população é quase 30 vezes maior do que a renda média dos $40 \%$ mais pobres (FOLHA DE SÃO PAULO, 18/06/96).

Esta desigualdade é observada no âmago do trabalho, uma vez que o local que o individuo ocupa na sociedade reflete o lugar que ocupa no sistema produtivo. Sem dúvida alguma podemos afirmar que quanto maior for a desigualdade social maior será a repercussão na qualidade de vida da sociedade de uma forma geral e do indivíduo e sua 
família em particular. Nesta ótica, é necessário ficar atento à amplitude desse processo de acumulação capitalista não perdendo de vista a situação do(a) trabalhador(a) também fora do espaço físico do trabalho, ou seja, sua vida enquanto cidadão(ã), na esfera privada.

Acreditamos que o empobrecimento populacional do pais exerce influências significativas no processo de envelhecimento individual e na qualidade de saúde, uma vez que a saúde individual não se limita às suas dimensões biológica e psicológica; ao contrário, está diretamente relacionada com as condições de vida dos seres humanos e sofre influência significativa das políticas sociais e econômicas adotadas pelos países.

Segundo SINGER (1996) estamos vivendo a Terceira Revolução Industrial, caracterizada pela "terceirização" da força de trabalho, que é responsável pela transformação de empregos formais em ocupações e por tirar do(a) trabalhador(a) as garantias e os direitos trabalhistas conquistados até então. Para SINGER a Terceira Revolução Industrial "afeta profundamente os processos de trabalho e, com toda certeza expulsa do emprego milhões de pessoas que cumprem tarefas rotineiras, que exigem um repertório limitado de conhecimentos e, sobretudo, nenhuma necessidade de improvisar em face de situações imprevistas. É neste tipo de tarefas que o cérebro eletrônico se mostra superior ao humano, tanto em termos de eficiência quanto de custos". (SINGER, 1996).

No caso do Brasil o desassalariamento de parcela crescente da População Economicamente Ativa e a expansão das ocupações nos segmentos não-organizados e do desemprego têm ocorrido "paralelamente ao abandono do projeto de industrialização nacional e a adoção de políticas macroeconômicas de reinserção internacional e enfraquecimento do estatuto do trabalho". (POCHMANN, 1977). Segundo POCHMANN (1997) essas transformações nas formas de ocupação dos(as) trabalhadores(as), que expressam uma desestruturação do mercado de trabalho, tiveram início no Brasil nos anos oitenta, com a crise da divida externa, que levou o país a adotar um conjunto de programas de ajustes macroeconômicos que até hoje inviabilizam a retomada sustentada do crescimento econômico.

Nesta perspectiva podemos afirmar que vivemos um período de precarização do trabalho, caracterizado pela terceirização dos serviços, surgimento de relações informais ou incompletas de emprego, desregulamentação dos direitos do trabalho conquistados em leis e contratos coletivos, gerando insegurança no emprego, dificuldade de organização sindical, colocando em risco a solidariedade entre os(as) trabalhadores(as). 
Para organizar o processo de trabalho os(as) capitalistas criam formas de gestão do trabalho, com o objetivo de racionalizar a produção, obter maiores lucros, disciplinando os corpos individuais e coletivos dos(as) trabalhadores(as). Vivemos neste momento histórico uma transição entre o Fordismo e o Toyotismo ou "modelo japonês". O fordismo se caracteriza pela "produção em massa, através da linha de montagem e de produtos mais homogêneos; através do controle dos tempos e movimentos pelo cronômetro fordista e produção em série taylorista; pela existência do trabalho parcelar e pela fragmentação das funções; pela separação entre elaboração e execução no processo de trabalho; pela existência de unidades fabris concentradas e verticalizadas e pela constituição/ consolidação do operário-massa, do trabalhador coletivo fabril, entre outras dimensões". (ANTUNES, 1995). O toyotismo, por sua vez, se baseia na predominância do pensamento e de políticas conservadoras de corte neoliberal, na privatização das empresas públicas, na desregulamentação e flexibilização dos direitos do trabalho, na redução dos postos de trabalho, na produção flexivel produzida pela demanda/ consumo, na ausência de estoques, na terceirização do emprego, entre outras tantas. Desta forma o toyotismo complexificou, fragmentou e heterogeneizou ainda mais a classe que vive do trabalho; intelectualizou o trabalho manual ao mesmo tempo que desqualificou e sub-proletarizou parcela significativa dos(as) trabalhadores(as). (ANTUNES, 1995).

Podemos depreender desta situação de transição de modelos a prevalência do pensamento neoliberal, causando perversas conseqüências no interior do mercado de trabalho em particular e da sociedade de uma forma geral. Esse processo apresenta características mundiais delineadas pela retração das politicas públicas nas áreas da saúde, educação e promoção social e pela redução das conquistas sociais válidas para o conjunto da população, provocando um aumento da desigualdade e exclusão social. IANNI (1996) adverte que vários aspectos desta problemática convergem no fenômeno do desemprego, podendo acentuar a gravidade da questão social e das tensões que a constituem. Segundo esse autor, a partir dai surgem problemas "relativos aos preconceitos de raça, idade e sexo, tanto quanto os referentes à religião e língua, cultura e civilização" (IANNI, 1996). Salienta que na medida em que se acelera o processo de globalização do capitalismo, proliferam-se "os racismos de todos os tipos sociais, formas culturais, cores raciais. São ingredientes ativos da questão social, junto com o preconceito de sexo e idade, que se aguçam e generalizam em escala mundial" (IANNI, 1996). Reafirmamos que tal fenômeno tem tornado cada vez mais complexa a organização dos(as) trabalhadores(as), assim como a formação da consciência social dos(as) operários(as). 


\section{CONSIDERAÇÕES FINAIS}

Neste contexto reintroduzimos à discussão a complexidade da intermediação entre as áreas do Envelhecimento, da Saúde e do Trabalho. Acreditamos que a compreensão dos processos descritos nos permite ampliar a dimensão da nossa prática enquanto profissional da área da saúde, na medida em que fornece subsídios para que possamos ir além da concepção da saúde individual, remetendo-nos às questões estruturais e políticas na esfera da saúde coletiva. Desta forma, podemos afirmar que falar sobre saúde e envelhecimento com vistas a qualidade de vida neste momento em que a precarização do trabalho e a exclusão social são realidade mundial é o grande desafio colocado para os profissionais da área da Gerontologia e da Saúde Coletiva.

Não pretendemos neste estudo dar respostas a esse processo, até porque não as temos, também não estamos olhando de fora o problema, estamos inseridas nele, como trabalhadoras, como cidadãs. Entretanto sustentamos o pensamento de BRECHT de que "a única finalidade da ciência está em aliviar a miséria da existência humana". Desta forma trazemos o problema da precarização do emprego, da desigualdade e exclusão social para dentro das áreas da Saúde e da Gerontologia, pois acreditamos ser necessário tomarmos consciência de que o processo saúde-doença e o envelhecimento individual e populacional extrapolam esses campos teóricos. Portanto é na esfera da Ética que compreenderemos que a doença e os agravos não são problemas de ordem médica; ao contrário, demandam o esforço concentrado de toda a sociedade - não só da acadêmica - para buscar formas de reinventar o presente. Da mesma forma, acreditamos que de nada vale a Gerontologia "aumentar" os anos de vida dos seres humanos, senão se comprometer ética e politicamente em assegurar a qualidade de vida desses anos. Precisamos romper com a onipotência do discurso para viabilizar a prática gerontológica e sanitarista.

BEAUVOIR (1990) reforça esse pensamento ao mencionar que mais escandaloso do que o tratamento destinado à velhice é o tratamento que a sociedade inflige à maioria dos seres humanos na juventude e maturidade. Salienta que "a sociedade pré-fabrica a condição mutilada e miserável que é o quinhão deles na última idade. É por culpa dela que a decadência senil começa prematuramente, que é rápida, fisicamente dolorosa, moralmente horrivel porque esses indivíduos chegam a ela com as mãos vazias. Explorados, alienados, quando a força os deixa, tornam-se fatalmente 'refugos', 'destroços'." (BEAUVOIR, 1990). Para ela, a sociedade só se preocupa com os indivíduos na medida em que produzem força de trabalho, são mercadorias que devem ser consumidas. Para a sociedade capitalista só 
o lucro conta, a preservação da saúde do(a) trabalhador(a) ocorre apenas na dimensão da manutenção da força de trabalho; a qualidade de vida inerente à melhores condições de envelhecimento é privilégio de uma parcela pequena da sociedade, composta pelos(as) exploradores(as). BEAUVOIR (1990) destaca que os(as) trabalhadores(as) conquistaram direitos trabalhistas e direitos sociais capazes de reintegrá-los(as) à humanidade; no entanto, salienta que valem apenas quando são produtivos(as) e necessários(as) ao capital.

Acreditamos que a classe social é um determinante significativo da qualidade de saúde, de envelhecimento e de vida dos seres humanos. Segundo BEAUVOIR (1990) "a tragédia da velhice é a radical condenação de todo um sistema de vida mutilador: um sistema que não fornece à imensa maioria das pessoas que fazem parte dele uma razão de viver. $O$ trabalho e a fadiga mascaram essa ausência: ela se descobre no momento da aposentadoria. É muito mais grave do que o tédio. Ao envelhecer, o trabalhador não tem mais lugar no mundo, porque, na verdade, nunca lhe foi concedido um lugar: simplesmente, ele não tivera tempo de perceber isso. Quando se dá conta, cai numa espécie de desespero bestificado".

Assim, ao se buscar estudar o processo de envelhecimento e suas implicações na saúde individual e coletiva é necessário ficar atento(a) às diferenças sociais postas, pois na verdade o que está em jogo é todo o sistema de desigualdade social vivenciado pelos seres humanos, onde o grande desafio centra-se na mudança radical do estilo de vida dos individuos.

\section{REFERÊNCIAS BIBLIOGRÁFICAS}

ALONSO, J.A.M. Aspectos sociologicos del proceso de envejecimiento. Quadern CAPS, 1995.

ANTUNES, R. Adeus ao trabalho: ensaio sobre as metamorfoses e a centralidade do mundo do trabalho. $2^{a}$ ed, São Paulo, Cortez Editora da UNICAMP, 1995.

ARIĖS, P. História social da criança e da família. Rio de Janeiro, Editora Guanabara, 1991.

BEAUVOIR, S. A velhice. Rio de Janeiro, Nova Fronteira, 1990.

BENTOV, M. et al. Envejecimiento y bienestar. In: DORESS, P.B.; SIEGAL, L., org. Envejecer juntas. Barcelona, Ed. Paidós, 1993. p. 23-44. 
BOBBIO, N. De senectute e altri scritti autobiografici. Torino, Einaudi Editore, 1996.

BORBA, F.S., coord. Dicionário gramatical de verbos do português contemporâneo do Brasil. $2^{a}$ ed., São Paulo, Editora UNESP, 1991.

BRASIL. Constituição da República Federativa do Brasil. Brasília, 1988.

BRASIL. Lei $n^{\circ}$ 8.842- Dispõe sobre a política nacional do idoso, cria o Conselho Nacional do Idoso e dá outras providências. Brasília, 04 de janeiro de 1994.

BRÊTAS, A.C.P. As enfermeiras, o poder, a história: um estudo exploratório sobre mentalidades. Campinas, 1994. [Dissertação de Mestrado; Universidade Estadual de Campinas].

BRÉTAS, A.C.P. Envelhecimento e trabalho. In: OLIVEIRA, E.M.; SCAVONE, L., org. Trabalho, saúde e gênero na era da globalização. Goiânia, AB Editora, 1997. p.61-67.

CAMPOS, G.W.S. Considerações sobre a arte e a ciência da mudança: a revolução das coisas e reforma das pessoas; o caso da saúde. In: CECÍLIO, L.C.O., org. Inventando a mudança na saúde. $2^{a}$ ed., São Paulo, HUCITEC, 1997. p. 29-87.

CANGUILHEM; G. O normal e o patológico. $4^{\text {a }}$ ed. Rio de Janeiro, Forense Universitária, 1995.

CAPONI, G. A concepção do cuidado e a especificidade da enfermagem geriátrica e gerontológica. Texto Contexto Enf., 6(2):51-56, 1997.

CAPRA, F. O ponto de mutação. São Paulo, Cultrix, 1995.

CARVALHO FILHO, E.T. \& ALENCAR, Y.M.G. Teoria do envelhecimento. In: CARVALHO FILHO, E. T., org. Geriatria: fundamentos, clínica, terapêutica. São Paulo, Atheneu, 1994. p. 1-8.

CASUCCI, M.A.A. Psicogerontologia: attualità e nuove prospecttive. In: URBANI, G., org. L'Anziano Attivo: proposte e riflessioni per la terza e la quarta età. Torino. Edizioni della Fondazione Giovanni Agnelli, 1991. p. 53-69. 
DEBERT, G.G. Pressupostos da reflexão antropológica sobre a velhice. In: DEBERT, G.G., org. Antropologia e Velhice. Campinas, IFCH/ UNICAMP, 1994. p. 7-30. (Textos Didáticos, 13).

DEBERT, G.G. Envelhecimento e curso da vida. Rev. Estudos Femin. 5(1):120-8, 1997.

ENGELS, F. O papel do trabalho na transformação do macaco em homem. $4^{a}$ ed. São Paulo, Global Editora, 1990.

FEATHERSTONE, M. O curso da vida: corpo, cultura e o imaginário no processo de envelhecimento. In: DEBERT, G.G., org. Antropologia e Velhice. Campinas, IFCH/ UNICAMP, 1994. p. 49-71. (Textos Didáticos· 13).

FEATHERSTONE, M. A velhice e o envelhecimento na pós-modernidade. Terceira Idade, SESC, 10(14):5-17, 1998.

FERRARA, F. et al. Medicina de la comunidad. $2^{\mathrm{a}}$ ed., Buenos Aires, Intermédica, 1976.

FERREIRA, A.B.H. Novo dicionário da língua portuguesa. Rio de Janeiro, Nova Fronteira, 1985.

FOUCAULT, M. Vigiar e punir. 10ª ed. Petrópolis, Vozes, 1993.

GOMES, F.A.A. Histórico da geriatria e gerontologia. In: SBGG-RJ. Caminhos do envelhecer. Rio de Janeiro, Revinter, 1994. p.1-5.

GUIMARÃES, R.M. O processo de envelhecimento como campo de investigação. Gerontologia, 5(1): 18-22, 1997.

HABERMAS, J. Teoría de la acción comunicativa: crítica de la razón funcionalista. Madrid, Taurus, 1987.

HUBERMAN, L. História da riqueza do homem. $21^{a}$ ed. Rio de Janeiro, Editora Guanabara, 1986.

IANNI, O. O mundo do trabalho. In: FREITAS, M.C., org. A reinvenção do futuro. São Paulo, Cortez/ UFS-IFAN, 1996. p. 15-54. 
MARX, K. Salário, preço e lucro. $4^{\mathrm{a}}$ ed. São Paulo, Global Editora, 1985.

MARX, K. \& ENGELS, F. Manifesto do partido comunista. Impresso na URSS, Edições Progresso, 1987.

MARX, K. O Capital: crítica da economia política. 16ª ed. Rio de Janeiro, Civilização Brasileira, 1998. Livro I.

MINISTÉRIO DA SAÚDE. Lei orgânica da saúde. $2^{a}$ ed. Brasilia, Ministério da Saúde, Assessoria de Comunicação Social, 1991.

ORGANIZACIÓN MUNDIAL DE LA SALUD. Documentos básicos. 26ª ed., Ginebra, 1976.

ORGANIZAÇÃO MUNDIAL DE SAÜDE. Cuidados primários de saúde. Alma-Ata, URSS, OMS/ UNICEF, 1979.

PERLADO, F. Teoria y práctica de la geriatria. Madrid, Ed. Diaz de Santos, 1995.

POCHMANN, M. Traços gerais do movimento de desestruturação do mercado de trabalho brasileiro. Campinas, Instituto de Economia, UNICAMP, 1997.

QUALIDADE DE VIDA 2: relatório da ONU constata que concentração de renda é uma das maiores do mundo. Folha de São Paulo, 18 de jun. 1996. p.7.

ROBLEDO, L.M.G. Concepción holística del envejecimiento. In: ANZOLA PÉREZ, E. et al, org. La atención de los ancianos: um desafío para los años noventa. Washington D.C., OPS, 1994. p. 34-41.

SAYEG, M.A. \& PEREIRA, S.R.M. Perfil de desempenho do geriatra e do gerontólogo. In: SBGG-RJ. Caminhos do envelhecer. Rio de Janeiro, Revinter, 1994. p.35-38.

SINGER, P. Desemprego e exclusão social. S. Paulo em Perspec. 10(1): p. 3-12, 1996.

VIEIRA, L. Cidadania e globalização. Rio de Janeiro, Record, 1997.

WAGNER, E.C.A.M. As dimensões individuais no envelhecimento. In: PEREIRA, D.A., org. Idoso: encargo ou patrimônio? O envelhecer em São Paulo. São Paulo, Proposta Editorial, 1992. p. 73-78. 
WHO/ WORLD HEALTH ORGANIZATION. Uses of epidemiology in aging; report of a scientific group. 1984. (WHO - Techinical Report Series 706).

\title{
INTERSECTION POINTS BETWEEN THE GERONTOLOGICAL, HEALTH AND WORKING KNOWLEDGE AREAS: QUESTIONS FOR REFLECTIONS
}

\begin{abstract}
The present study is intended to present and discuss a number of selected theoretical referents concerning the Gerontology, Health and Work knowledge areas. It seeks the mediation between those areas in order to understand the meaning of the aging process when related to the working market and its implications either for individual or collective health. The study was developed within historical and political contexts based on the globalization phenomenon, with the predominance of neoliberal policies thought. From this point of view, it discusses the productive changes the work market has been presenting while emphasizing the structural unemployment problem and its consequences for individual and collective health and aging processes.
\end{abstract}

KEY WORDS: Health, Aging process, Work. 